\title{
Study on Sheep Farming Sustainable Development in Ili Region Ziqun Wang ${ }^{1, a}$ \\ ${ }^{1}$ College of Economics and Management, Tarim University, Alar, XinJiang, 843300 \\ a email
}

Keywords: Sheep Farming, Sustainable Development, Illi Region

\begin{abstract}
Lamb is the daily life of common meat on the table homemade also more common. At present, China's sheep industry has been rapid development of sheep farming industry has made considerable progress. However, compared with other meat production, the proportion of lamb production is very small, averaging only $0.12 \%$, so the lamb industry market prospect is very broad. Ili region is one of the developed areas of animal husbandry and sheep breeding has a long history in recent years in the sheep breeding is also a series of problems have constrained the development of sustainable sheep farming in the region, this paper sheep Ili State Discussion on sustainable development of aquaculture
\end{abstract}

\section{Introduction}

Historical development of animal husbandry in Xinjiang Ili region very long, at present, Ili region of Xinjiang has become an important production base and livestock breeding stock breeding base. Ili grassland region 1 8,951,200 hm2, of which natural grassland 18,791,000 hm2; unused land 4.0907 million hm2. Ili Xinjiang region provides 13\% of the slaughter of sheep and lamb products.

Ili end of 2012 amounted to 4.214 million sheep herds. At the end of 2013 all kinds of livestock 13,287,000 (only), of which 3 million sheep. Bashibai 600,000 sheep; Altay tailed sheep 2 million. Currently, sheep farming region of Xinjiang Ili region include pastoral animal husbandry, farming and animal husbandry and agro-pastoral livestock breeding zone structure, showing ternary structure system, as shown in Table 1 below.

Tab 1 Ili district culture structure

\begin{tabular}{|c|c|c|}
\hline structure & Name & Number \\
\hline $\begin{array}{l}\text { Animal husbandry } \\
\text { County }\end{array}$ & $\begin{array}{l}\text { Xinyuan County、Zhaosu County、Tekese } \\
\text { County、Nileke County }\end{array}$ & 4 \\
\hline $\begin{array}{l}\text { Semi agricultural and } \\
\text { semi pastoral counties }\end{array}$ & Gongliu County & 1 \\
\hline Agricultural county & $\begin{array}{l}\text { Yining city、Yining County、Huocheng } \\
\text { County、Chabuzhaer County、Kuitun County }\end{array}$ & 5 \\
\hline
\end{tabular}

According to the Bureau of Animal Husbandry Ili statistics, as of the end of June 2015 Ili sheep population amounting to $6,290,100$, representing an increase of $1.46 \%$ last year, to reach 3.5002 million breeding ewes. Grassland is overloaded. Such as: Yining can put stocking rate of 124000 (standard sheep), last year the number was 160,000 population, this year has reached 172,000 . The first half of 2015, Ili sheep slaughter number 1,605,300, down 2.51\%; mutton production has reached 27,998.6 tons, down 2.6\% [7].

\section{Comprehensive Evaluation Method in Ili Prefecture Sheep Breeding for Sustainable Development}

In this study, mainly sheep breeding Ili region Sustainable Development Evaluation Model, and thus the sustainable development of sheep farming in Ili Prefecture conducted a comprehensive evaluation, to provide a basis for the implementation of the strategy in Ili region sheep industry sustainable development.

Evaluation Method. Entropy method refers to the amount of information provided in accordance 
with the size of the observed values of the indicators to determine a method of weights. Entropy is an important concept from thermodynamics, and it began to be used in the research into information theory to explain the status of the signal sent by a source degree of uncertainty. Entropy is used to illustrate the relative importance of the evaluation, the basic idea is that if the degree of difference evaluation bigger and more important, its weight will be higher. Then the step of determining the specific entropy is as follows:

First, obtain statistics evaluation index, set its matrix as follows:

$$
\begin{aligned}
& R=(r i j) \max ,(i=1, \ldots \ldots, m ; j=1, \ldots \ldots, n) \\
& {\left[\begin{array}{cccc}
r_{11} & & \ldots & r_{1 n} \\
& & \ldots & \\
\vdots & \vdots & \vdots & \vdots \\
r_{m 1} & & \cdots & r_{m m}
\end{array}\right]}
\end{aligned}
$$

In the above formulas, $m$ is the number of the overall index, $n$ is the number of general areas, rij $\mathrm{j}$-th regional statistics on the i-th indicator. Depending on the selected index of specific content, select the original data assignment, reached these matrices. Since inconsistent indicators between specific units, be sure to after the original data standardization (ie standardized matrix R) and then obtain a standardized matrix of each index, the standardized formula is as follows:

$$
\begin{aligned}
& r_{i j}=\frac{r_{i j}-\min \left(r_{i j}\right)}{\max \left(r_{i j}\right)-\min \left(r_{i j}\right)} \\
& r_{i j}=\frac{\max \left(r_{i j}\right)-r_{i j}}{\max \left(r_{i j}\right)-\min \left(r_{i j}\right)}
\end{aligned}
$$

Among this, min (rij) is the minimum value of the index (in the row), on the contrary, max (rij) is the maximum value of the index (in the line) is. From the entropy principle point of view, if the index value is selected then the greater the value, the better, then using equation (1); If the value of the selected index is as small as possible, then using Equation (2).

Since the scope of the evaluation of the selected indicators is very large and units indicators are not uniform, so the first standardized raw data, thereafter calculate the index makes it possible entropy.

According to the definition of entropy in information theory, a set of information entropy data $E_{j}=-\ln (n)^{-1} \sum_{i=1}^{n} p_{i j} \ln p_{i j} p_{i j}=Y_{i j} / \sum_{i=1}^{n} Y_{4}$

If the definition of $p_{i j}=0 \lim _{p_{11}-0} p_{i j} \ln p_{i j}=0$

The information entropy formula to calculate the entropy for each index $E_{1}, E_{2}, \ldots, E_{k}$. Calculate the index through information entropy weights: $W_{i}=\frac{1-E_{i}}{k-\sum E_{i}}(i=1,2, \ldots, k)$

Comprehensive Evaluation: to determine the meaning of the study is the evaluation index system based on the use of certain methods to determine the importance of each index (in the area of research). In determining the evaluation Ili sheep industry index weights after the method has been applied to the sustainable development of transport sheep industry assessed. Specific evaluation model is as follows: $A S D=\sum_{j=1}^{n}(w i * c i)$

In this model, ASD is a comprehensive index, wi is a weighting value of the $\mathrm{i}$-th indicator $(0 \leqq$ wi $\leqq 1, \sum_{j=1}^{n} w i=1, \mathrm{Ci}$ is its dimensionless value, $\mathrm{n}$ is the number of evaluation index. If the value of the larger ASD, so overall level of sustainable development is higher.

Evaluation of selected. Ili assessment of sustainable development based on scientific sheep farming industry needs design and construction ideas. Evaluation Index System for Sustainable Development of sheep farming industry metrics structured that science can do reflect Ili sheep farming for sustainable development, and there is no overlap between the index Index phenomenon, to achieve sustainable development of sheep breeding scientific and rational evaluation. 
(2) the principle of completeness

About Ili sheep breeding industry in sustainable development, we need to sheep breeding chain of production processes to supply part of the lamb market, establish a comprehensive evaluation system that affect all aspects of sheep farming for sustainable development are the establishment of evaluation index, so as to achieve sustainable development of sheep breeding complete, comprehensive evaluation to obtain a more accurate evaluation results.

(3) operational principles of simplicity

In sheep breeding of Ili assessment of sustainable development, can create a lot of evaluation, based on availability needs, consider the representative and the easy access to survey data in order to select a representative indicator of actual survey data to be Evaluation.

Evaluation of selected. This article studies the target layer: horizontal Ili sheep breeding industry in sustainable development; layer according to the guidelines set three subsystems System for Sustainable Development sheep breeding industry, namely the natural environment, social and economic system of three. Additional related indicators are set forth below:

(1) Ecosystem Indicators

The election reflects the natural indicators of sustainable development in the process, four representation targets are selected, they are: corn yield C; precipitation C2; available groundwater C3; forage coverage $\mathrm{C}$.

(2) social indicators

Including animal husbandry population accounts for agriculture population ratio, per capita consumption of lamb and Engel coefficient. Livestock population ratio of the number of occupied agricultural population C5; per capita consumption of lamb C6; Engel coefficient C7; natural population growth rate C8.

(3) economic indicators

The indicators include indicators to measure the economic development of the region, of which there are animal husbandry output value accounted for the proportion of agricultural output value index C9; animal husbandry net head count C10; Livestock raising per capita household herds C11; C12, animal husbandry and added value .

Table 1-1 Ili region 2005--2014 Nian Sheep sustainable development indexes raw data table

\begin{tabular}{rrrrrrrrrrrr}
\hline & 2005 & 2006 & 2007 & 2008 & 2009 & 2010 & 2011 & 2012 & 2013 & 2014 \\
\hline C1 & 91.34 & 106.66 & 132.77 & 126.93 & 150.59 & 212.14 & 227.61 & 304.07 & 380.68 & 403.21 \\
C2 & 885 & 896.6 & 892.6 & 769.6 & 929.5 & 1065.4 & 1076.2 & 835 & 833.1 & 963.7 \\
C3 & 889 & 958 & 1195 & 1422 & 2024 & 2240 & 2680 & 2971 & 3681 & 4151 \\
C4 & 38.12 & 40.59 & 39.66 & 47.78 & 40.78 & 41.16 & 42.04 & 41.78 & 43.08 & 41.54 \\
C5 & 14.25 & 14.45 & 14.5 & 14.52 & 14.75 & 14.72 & 14.48 & 14.8 & 15.18 & 13.93 \\
C6 & 13.7 & 12.69 & 12.04 & 10.63 & 7.44 & 9.27 & 9.85 & 8.59 & 8.48 & 7.98 \\
C7 & 39.76 & 39.23 & 38.74 & 38.58 & 36.49 & 37.33 & 37.79 & 37.66 & 28.57 & 28.27 \\
C8 & 42.85 & 25.6 & 41.91 & 36.32 & 31.21 & 38.07 & 37.66 & 37.79 & 34.83 & 33.88 \\
C10 & 13.31 & 8.6 & 8.89 & 5.91 & 4.04 & 14.48 & 7.53 & 11.97 & 19.03 & 1.39
\end{tabular}




$\begin{array}{lrrrrrrrrrr}\text { C11 } & 125.08 & 121.66 & 114.31 & 84.58 & 98.52 & 96.41 & 98.93 & 94.1 & 91.91 & 90.96 \\ \text { C12 } & 147608 & 158934 & 202989 & 231622 & 275565 & 328957 & 393568 & 492478 & 610166 & 726501\end{array}$

Calculate the weight. After the use of standardized data, and in the use of the formula to calculate the entropy of each index and corresponding weights, such as

Table 1-2 each index and entropy weights

\begin{tabular}{lll}
\hline Index & Entropy & Weights \\
\hline C1 & 0.8192 & 0.1043 \\
C2 & 0.8970 & 0.0594 \\
C3 & 0.8323 & 0.0967 \\
C4 & 0.8961 & 0.0599 \\
C5 & 0.9263 & 0.0425 \\
C6 & 0.8573 & 0.0823 \\
C7 & 0.7577 & 0.1397 \\
C8 & 0.9341 & 0.0380 \\
C9 & 0.7644 & 0.1358 \\
C10 & 0.9012 & 0.0570 \\
C11 & 0.8661 & 0.0772 \\
C12 & 0.8140 & 0.1072
\end{tabular}

According to 2005-2014 10 Indicators underlying data, based on the above research model can be calculated to obtain the value of each index.

Table 1-3 Ili sheep farming sustainable development index

\begin{tabular}{ccccc}
\hline Year & Ecology & society & economic & $\begin{array}{c}\text { Sustainable } \\
\text { Development }\end{array}$ \\
\hline 2005 & 0.0047 & 0.0281 & 0.0468 & 0.0796 \\
2006 & 0.0112 & 0.0221 & 0.0229 & 0.0562 \\
2007 & 0.0134 & 0.0283 & 0.0298 & 0.0715 \\
2008 & 0.0233 & 0.0226 & 0.0105 & 0.0563 \\
2009 & 0.0244 & 0.0206 & 0.0176 & 0.0625 \\
2010 & 0.0374 & 0.0253 & 0.0238 & 0.0865 \\
2011 & 0.0438 & 0.0235 & 0.0291 & 0.0964 \\
2012 & 0.0421 & 0.0223 & 0.0500 & 0.1144 \\
2013 & 0.0560 & 0.0595 & 0.0706 & 0.1861 \\
2014 & 0.0640 & 0.0503 & 0.0762 & 0.1906 \\
\hline
\end{tabular}

As can be seen from Table 1-3, ecological indicators of change instability, social indicators also changes in instability, economic indicators showed a steady upward trend, indicating that: in the Ili region sheep breeding process, the economic indicators is the primary consideration. While economic development ignored the protection of the ecological environment, and the overall development of this phenomenon is consistent. Between 2006 and 2009 the region due to the impact of natural disasters, to the region's economy caused significant losses in Ili sheep farming sustainable economic development index table column, we can see that in recent years there have 
been marked changes in data .

\section{Discussions}

Through the study found, the technology factor inputs did not become an important support in Ili Prefecture sheep breeding development, which is another example of reflect the plight of the Ili region in the development of sheep breeding faced, not to explore a suitable sustainable development of sheep farming industry the way. In the above technical efficiency improvement, market development should be strengthened sheep breeding, and the use of modern management theory and methods, the establishment of sheep production base, to play on behalf of science and technology, the role of advanced management concepts in sheep production, attracting a number of professional and technical talent for large-scale sheep farming to provide technical support, provide technical support for the development of large-scale sheep farming in Ili Prefecture.

\section{Consideration Ili Area Sheep Breeding For Sustainable Development}

There should be insufficient aspect in terms of sheep breeding breeding technology, industrial planning, development and growth supporting measures in Ili Prefecture to think of sustainable development.

Strengthen the development and use of the advantages of resources. Natural grassland resources Ili region rich, a large part of these sheep farming is dependent on the quality of grassland resources, and therefore the need for these advantages to protect resources and development. Ili Kazak sheep breed area should be protected, and do breeding, purification and rejuvenation work. In the breeding process, should be selected on Biological Diversity, in order to maintain the diversity of germplasm resources, to lay the foundation for the future development of the individual and the good gene pyramiding, breeding new varieties.

Carry out industrial development. We should continue to strengthen against the pastoral herders to settle, build forage base, and grazing habits change, the implementation of summer grazing, winter feeding, so that artificial fodder to gradually replace the winter pastures. From herdsman, farmer's life begin production, breeding and production methods change, the implementation of the warm season grazing cool-season feeding + farming methods, thus promoting the development of sheep farming in Ili Prefecture modern industry. This way to the annual warm season grazing natural pastures six months, six months of cold season forage artificial feeding, cancel winter pastures to summer pastures and winter pastures into. For cold season feeding, livestock feed, grass and warm circle have generally able to maintain the original weight of the winter, as good breeding conditions, high level of management, but also livestock and winter weight gain of about $10 \%$.

Improve sheep breeding and production technology. Sheep in the Ili region to promote hybridization. Hybrid male should choose meat body better, and fast growth, good quality sheep, parental choice of strong local adaptability, and a large number of groups of species. In the above hybridization program should be based on the economic situation of farmers and farming techniques in different regions with different levels of Ili to be determined, and there is crossbred crossbred two different scenarios.

To enhance the level of supporting services. In the sheep breeding industry for the development of livestock sector in Ili Prefecture should actively improve the level of support services, the initiative to provide quality support services. Construction of sheep breeding industry, special teams, the sheep farming industry as the government an important part of the task, and subordinate county, township and other sharing and communication sheep breeding work under market economy conditions, should make full use of market mechanisms, development of animal husbandry innovative enterprises, building technology innovation strategic alliance to promote research institutes, universities and other enterprises to develop cooperation and the establishment of relevant research base, demonstration parks, complementary advantages. 


\section{References}

[1] Gao Pei-yuan, Huangling Di, Li Xinping, Liu Xuemei Min Jie Hu Dongxiu, Zhuxiu Juan Liu Nana, Yishan Jiang, Han Yongqiang Amat Jiang Luyang comparative analysis, Zhang Kai Xinjiang sheep breeding efficiency [J]. Finance \& Economics, 2013,03: 74-80.

[2] Ma Yanfei, Lin Peng Chao, Wu Jingtian sheep breeding technical measures [J]. Today Animal Husbandry and Veterinary Medicine, 2010 (11): 59-60.

[3] Purcell. Jiang-effective measures to improve sheep breeding [J]. Xinjiang Animal Husbandry, 2014 (01): 46-47.

[4] Guan Ying. Increase sheep production several economic measures [J]. Contemporary livestock and poultry breeding industry, 2013 (07): 26-27. 